\title{
Executive Council lists and general practitioner files
}

\author{
R. D. T. FARMER, E. G. KNOX, K. W. CROSS, AND D. L. CROMBIE \\ Health Services Research Centre, Department of Social Medicine, University of Birmingham B15 2TJ \\ and The Harborne Study Practice of The Royal College of General Practitioners
}

\section{SUMMARY}

An investigation of the accuracy of general practitioner and Executive Council files was approached by a comparison of the two. High error rates were found, including both file errors and record errors. On analysis it emerged that file error rates could not be satisfactorily expressed except in a time-dimensioned way, and we were unable to do this within the context of our study. Record error rates and field error rates were expressible as proportions of the number of records on both the lists; $79.2 \%$ of all records exhibited non-congruencies and particular information fields had error rates ranging from $0.8 \%$ (assignation of sex) to $68.6 \%$ (assignation of civil state). Many of the errors, both field errors and record errors, were attributable to delayed updating of mutable information.

It is concluded that the simple transfer of Executive Council lists to a computer filing system would not solve all the inaccuracies and would not in itself permit Executive Council registers to be used for any health care applications requiring high accuracy. For this it would be necessary to design and implement a purpose designed health care record system which would include, rather than depend upon, the general practitioner remuneration system.

\section{INTRODUCTION}

An Executive Council has an index of all persons registered with general practitioners in its area. This index is maintained alphabetically for the doctor with whom individuals are registered. A mechanism exists for adding newly registered people to a doctor's list and deleting people who have left or died. The Executive Council index is the most complete population file within the National Health Service. Its principal use at the present time is the calculation of payments to general practitioners. Potentially it would appear to have other uses, especially for health care planning; however, there are several obstacles to its full use in this way. Most immediately, there may be legal constraints to extensions of use beyond the designated purposes of these records, namely for computing payments to general practitioners and determining contractual responsibilities in case of complaint. However, registers are a prerequisite of many important elements of modern medical and nursing practice, especially those concerned with the maintenance of health rather than the care of established sickness, and the requirement is likely to grow. The issue that arises is whether health care files should continue to be constructed independently of each other, and of administrative files, or whether the opportunity should be taken to construct a unified system. Technically there are few problems, and it is certainly possible to adapt Executive Council lists and their existing manual processing to a computer operation. Indeed, it would almost certainly be profitable to do so even if no extension of function were contemplated and we may regard this as inevitable.

A plan to extend uses of an automated list would involve detailed consideration of mechanisms to protect confidentiality and of a wide range of design criteria related to the needs of the different branches of the Health Service and related services. Despite this complexity such a system would almost certainly be more satisfactory than the present fragmented arrangements for scheduling screening procedures and monitoring the health of individuals.

If current Executive Council lists are eventually made the basis of a unified system, then the accuracy of the existing files may make large differences to the ease and cost of the operation as well as to its detailed planning. Current inaccuracies, although known not to be trivial, lead at present only to mistakes in the allocation of sums of money, and even here the mistakes usually cancel themselves out. If the use of the files were extended to the manipulation of people, where errors do not cancel out and where their effects cannot be so readily 
written off, a much higher standard of accuracy could be called for. For these purposes it would be necessary that records held in different places (area administration, health centre, hospital, etc.) should agree precisely with each other and with the identification and other characteristics of the persons they represent.

There are many kinds of error and some may be inevitable. At any point in time, for example, a file will contain updating errors-people born who are not yet added, or persons who are dead but not yet removed from the register. Changes of address, of name, and of marital status, while the individual remains in the same area and registered with the same general practitioner, will introduce similar errors which take time to record. Levels of error here will depend partly upon the behaviour of patients and partly upon deliberate operational decisions based upon limits of unacceptable consequences and of acceptable costs.

One class of error, whose subtypes and frequencies can be measured now, is especially important to the formulation of initial policy. These are the errors of non-correspondence between files held in the Executive Council offices and those held by the general practitioners. The present study begins at this point and attempts to identify and to describe the different kinds of error occurring at this level and to assess their frequencies.

\section{Method}

The investigation formed part of a larger experimental development of general practice records systems and a study of their influence upon general practice methods. The basic method of file construction for the system (Farmer and Cross, 1972) involved a typist copying out all the Executive Council records attributable to the doctors concerned in the practice; these typed records were subsequently transferred to punch cards and then to magnetic tape. Before entry to the magnetic tape the cards were verified for punching errors and examined for syntactic and field errors by a validation program. The record-validation process generated a secondary level of error checking against the original Executive Council lists and resulted in a punch card/magnetic tape/computer-print version of the original list, accurate except for such residual errors as were incapable of detection by the validation routines. There were approximately 12,500 patients on this list.

The next step consisted in the production by the computer of sheets of self-adhesive labels, each printed with all the recorded items of an Executive
Council record. Each label was checked visually against the material recorded on the general practitioners' EC3/4 envelopes. Labels with accurate ? data were stuck on the envelopes, but labels which $\overrightarrow{\bar{F}}$ could not be matched with the envelopes, envelopes $\overrightarrow{0}$ which were not identifiable with labels, and labels which could be identified with envelopes but which had errors of content were set aside.

Finally, the three main sets of errors were checked against original Executive Council lists के to eliminate any typing errors which might have $\overrightarrow{0}$ escaped the validation routines.

The information fields on which these transfer and matching operations were based were:

Field 1 Surname

Field 2 First forename

Field 3 First three letters of second fore-

\begin{tabular}{|c|c|}
\hline & name \\
\hline Field 4 & Sex \\
\hline
\end{tabular}

Field 5 Previous surname

Field 6 Date of birth

Field 7 Date of registration

Field 8 Doctor with whom registered

Field 9 Address

Field 10 NHS number

Field 11 Civil state

Finally, an examination was carried out of the detailed patterns of non-correspondence betweent Executive Council and general practitioner records in those cases where a linkage could nevertheless be established. The particular examination was limited $\stackrel{\circ}{\circ}$ initially to the records $(3,959)$ of one doctor but $\stackrel{2}{\Rightarrow}$ was later supplemented by samples of the lists of the other three.

\section{RESULTS}

It was our original intention to make separate $\stackrel{\odot}{\supset}$ statements of frequencies of two kinds of errors (a) file errors, by which we mean non-correspon- 3 dences of identity in the two lists, and (b) record 8 errors, by which we mean non-correspondences of 3 detail, including missing information, in those $\mathrm{O}$ paired records which to human judgement belonged to the same person. While we achieved our objectives satisfactorily with respect to record errors we encountered an unexpected problem with the file of errors which prevented an exact statement.

The file error problem arose from the fact that the N process of transfer and collation took time, during which the general practitioner lists exhibited a substantial turnover. In this particular practice there are some 36 additions to, and some 30 deletions $\stackrel{D}{-}$ from, the practice each week. The main part of the file transfer and checking process took about nine ${ }_{0}^{-}$ 
weeks and the 350 (approximately) additions to the Executive Council list during this time were entered to the card/magnetic-tape file as they were encountered. Deletions, however, were not removed on the same basis.

The initial file transfer operation was designed to continue as a running system of updating, the two processes to overlap. The result was a complex system of time-delay errors which prevented a valid point-in-time statement of non-correspondences between the two files. A meaningful statement of error-rates of this kind would probably have to be time-dimensioned and include rate-of-transfer measurements, together with distributions of interval lengths between the different steps of the registration/ de-registration/transfer processes. It would have to be based upon quality control techniques, applied to a continuing system, similar to the one which we have now developed and not upon an ad hoc investigation of the kind attempted.

There was, however, one particular kind of file non-correspondence which permitted a 'prevalence' type of statement, namely the frequency of duplicated records. We encountered approximately 40 examples of duplication in the Executive Council lists and approximately 100 examples in the general practitioner envelopes.

\section{RECORD ERRORS}

The numbers of non-correspondences per record pair are expressed as a frequency distribution in
Table I. The Table also expresses the distribution as percentages of the total number of matched pairs. Of the 3,959 paired records belonging to one of the doctors, $3,130(79 \cdot 2 \%)$ failed to match exactly. This error rate was higher than we had anticipated and in order to see whether it was representative we subsequently examined samples of 200 record pairs from each of the other doctors. These results are also given in Table I and confirm that rates of this order were general throughout the practice.

\section{FIELD ERRORS}

Table II analyses the 5,358 errors enumerated in Table I according to the information field in which they occurred. It is not possible from examination of these data alone to say with certainty which of the differing records (or both) is wrong, nor even to be sure that record pairs corresponding in all details necessarily represent the characteristics of, or even the existence of, a living patient. Indeed, we know from subsequent uses of our 'clean' files for scientific and practice management purposes that this is not always so. However, many of the errors were susceptible to interpretation on common sense grounds.

NAmes. It was evident that many of the surname errors were due to change of name on marriage, the general practitioner having been informed, but not the Executive Council. Forename discrepancies

TABLE I

FREQUENCY DISTRIBUTION OF NUMBER OF NON-CONGRUENT FIELDS PER RECORD EXAMINED

\begin{tabular}{|c|c|c|c|c|c|c|c|c|c|c|c|}
\hline \multirow{2}{*}{\multicolumn{2}{|c|}{ Sample }} & \multirow{2}{*}{\multicolumn{2}{|c|}{$\begin{array}{l}\text { No. of Records } \\
\text { Examined }\end{array}$}} & \multicolumn{8}{|c|}{ Non-congruences per Record } \\
\hline & & & & \multicolumn{2}{|c|}{1} & \multicolumn{2}{|c|}{2} & \multicolumn{2}{|c|}{3} & \multicolumn{2}{|c|}{4} \\
\hline $\begin{array}{l}\text { Total list Dr. A } \\
\text { Sample list Dr. B } \\
\text { Sample list Dr. C } \\
\text { Sample list Dr. D } \\
\text { Lists B, C, D }\end{array}$ & $\begin{array}{l}\ldots \\
\ddot{*} \\
\cdots\end{array}$ & $\begin{array}{r}3,959 \\
193 \\
200 \\
200 \\
593\end{array}$ & $\begin{array}{l}(100) \\
(100) \\
(100) \\
(100) \\
(100)\end{array}$ & $\begin{array}{r}2,165 \\
79 \\
125 \\
119 \\
323\end{array}$ & $\begin{array}{l}(54 \cdot 7) \\
(40 \cdot 9) \\
(62 \cdot 5) \\
(59 \cdot 5) \\
(54 \cdot 4)\end{array}$ & $\begin{array}{r}639 \\
51 \\
32 \\
35 \\
118\end{array}$ & $\begin{array}{l}(16 \cdot 1) \\
(26 \cdot 4) \\
(16 \cdot 0) \\
(17 \cdot 5) \\
(19 \cdot 8)\end{array}$ & $\begin{array}{r}243 \\
19 \\
16 \\
4 \\
39\end{array}$ & $\begin{array}{l}(6 \cdot 1) \\
(9 \cdot 8) \\
(8 \cdot 0) \\
(2 \cdot 0) \\
(6 \cdot 5)\end{array}$ & $\begin{array}{r}88 \\
5 \\
5 \\
2 \\
12\end{array}$ & $\begin{array}{l}(2 \cdot 2) \\
(2 \cdot 5) \\
(2 \cdot 5) \\
(1 \cdot 0) \\
(2 \cdot 0)\end{array}$ \\
\hline
\end{tabular}

Percentages are given in parentheses.

TABLE II

FIELD NON-CONGRUENCES IN RECORDS

\begin{tabular}{|c|c|c|c|c|c|c|c|c|c|c|c|}
\hline \multicolumn{2}{|l|}{ Field } & \multicolumn{2}{|c|}{ Dr. A } & \multicolumn{2}{|c|}{ Dr. B } & \multicolumn{2}{|c|}{ Dr. C } & \multicolumn{2}{|c|}{ Dr. D } & \multicolumn{2}{|c|}{ Drs B, C, D } \\
\hline $\begin{array}{l}\text { Records examined } \\
\text { Sex .. } \quad . \\
\text { Surname } \quad . . \\
\text { Forename I } \quad . \\
\text { Forenane II } . . \\
\text { Maiden name.. } \\
\text { Date of birth } \\
\text { Date of registration } \\
\text { Address } \quad . . \\
\text { NHS No. } \quad . . \\
\text { Civil state } \quad . .\end{array}$ & $\begin{array}{l}\because \\
\because \\
\because \\
\because \\
\because \\
\because \\
\because \\
.\end{array}$ & $\begin{array}{r}3.959 \\
27 \\
58 \\
70 \\
134 \\
97 \\
285 \\
439 \\
668 \\
167 \\
2,678\end{array}$ & $\begin{array}{l}(0 \cdot 7) \\
(1 \cdot 5) \\
(1 \cdot 8) \\
(3 \cdot 4) \\
(2 \cdot 5) \\
(7 \cdot 2) \\
(11 \cdot 1) \\
(16 \cdot 9) \\
(4 \cdot 2) \\
(67 \cdot 6)\end{array}$ & $\begin{array}{r}193 \\
0 \\
2 \\
3 \\
5 \\
5 \\
23 \\
27 \\
57 \\
19 \\
121\end{array}$ & $\begin{array}{l}(0 \cdot 0) \\
(1 \cdot 0) \\
(1 \cdot 6) \\
(2 \cdot 6) \\
(2 \cdot 6) \\
(11 \cdot 9) \\
(14 \cdot 0) \\
(29 \cdot 5) \\
(9 \cdot 8) \\
(62 \cdot 7)\end{array}$ & $\begin{array}{r}200 \\
4 \\
2 \\
4 \\
5 \\
8 \\
15 \\
29 \\
17 \\
9 \\
172\end{array}$ & $\begin{array}{r}(2 \cdot 0) \\
(1 \cdot 0) \\
(2 \cdot 0) \\
(2 \cdot 5) \\
(4 \cdot 0) \\
(7 \cdot 5) \\
(14 \cdot 5) \\
(8 \cdot 5) \\
(4 \cdot 5) \\
(\varepsilon 6 \cdot 0)\end{array}$ & $\begin{array}{r}200 \\
1 \\
6 \\
0 \\
5 \\
7 \\
7 \\
1 \\
15 \\
17 \\
1 \leq 0\end{array}$ & $\begin{array}{l}(0 \cdot 5) \\
(3 \cdot 0) \\
(0 \cdot 0) \\
(2 \cdot 5) \\
(3 \cdot 5) \\
(3 \cdot 5) \\
(0 \cdot 5) \\
(7 \cdot 5) \\
(8 \cdot 1) \\
(75 \cdot 0)\end{array}$ & $\begin{array}{r}593 \\
5 \\
10 \\
7 \\
15 \\
20 \\
45 \\
56 \\
89 \\
45 \\
443\end{array}$ & $\begin{array}{l}(0 \cdot 8) \\
(1 \cdot 6) \\
(1 \cdot 1) \\
(2 \cdot 5) \\
(3 \cdot 3) \\
(7 \cdot 5) \\
(9 \cdot 6) \\
(15 \cdot 9) \\
(7 \cdot 5) \\
(74 \cdot 7)\end{array}$ \\
\hline
\end{tabular}


usually arose out of missing data. 'Previous surname' errors arose from reasons similar to surname errors so that the doctor's record was usually correct and the Executive Council's wrong. When a change of name took place either the general practitioner or the Executive Council were informed. It was apparent that there was litttle co-ordination between the two processes in maintaining accurate updated files.

Sex. Conflicting recording of sex in nearly $1 \%$ of record pairs was unexpected. In many instances the sex was omitted from one or other of the records. This was mainly among immigrants where the sex was not clear from the forename.

DATE OF BIRTH. Errors occurred in one in every 15 pairs and they have a serious implication for record linkage procedures depending upon date of birth. In $0.2 \%$ of records the non-correspondence consisted of a missing date or a missing element in the general practitioner records, in $1.5 \%$ it consisted of a similar deficiency in the Executive Council record, and in the remainder it consisted of two completely stated but different dates.

Date of Registration with General PracTITIONER. These elements showed non-correspondences in almost $11 \%$ of cases. This is particularly surprising since the date of registration is entered on the envelope before it is sent to the doctor and this takes place simultaneously with, and is part of, the Executive Council registration procedure. Many of these non-congruences arose from the fact that a number of patients were transferred en bloc from deceased and retiring partners to one of the surviving doctors.

ADDREss. Most of the address errors, found in $16.6 \%$ of pairs, were changes reported to the doctor but not to the Executive Council. Presumably there is another proportion, over and above this $16.6 \%$, where changes of address have occurred but have not yet reached the doctor.

Civil State. Errors of civil state were much the most frequent, occurring in $68.6 \%$ of all pairs. Clearly, this is the least reliable of all the elements recorded. Many of the errors were single or conjoint omissions rather than non-correspondences. In many of the cases where civil state was recorded on one record but not on the other, even the recorded version was known in fact to be wrong.

NHS Number. The error rate of the NHS number was remarkably low, less than $5 \%$ of record pairs exhibiting non-correspondence or omission. This proportion is greater than that of the surname alone, or either of the two forenames alone, but less than the sum of the individual error rate of the separate name components. The independent? sources of errors for the different name components suggest that accurate NHS number identifications are probably available at least as often as those based upon the names and date of birth. NHS numbers are, of course, unique and, even with an error rate, provide a high level of specificity (Farmer and Cross, 1973). This is especially important in of large file systems where identification errors may $\vec{\circ}$ lead not only to a failed record link, but occasionally to a wrong record.

\section{Discussion AND Conclusions}

The first conclusion is that there are substantial 9 non-congruences between Executive Council and general practitioner lists. Many of these differences arise from updating inaccuracies which will eventually be corrected, but at any one time they probably involve a substantial proportion of all records. The exact proportion appears to be indefinable except in the context of monitoring procedures applied to a running system. With present file maintenance arrangements it is unlikely that a high level of current accuracy could ever be achieved. So long as the Executive Council file is used only as a basis fo distributing a fixed total remuneration, and so long as the present approximations are acceptable, this may not matter too much. However, our evidence suggests that the present system is unlikely to be adequate for health care organization purposes.

Simple transfer of Executive Council lists to computer magnetic media would probably make the remuneration operation simpler, cheaper, quicker, and less subject to computational error. It might also improve file accessibility, improve the office component of the updating procedure, and help to control clerical errors. However, the transfer would not of itself cure many of the mistakes nor provide easily for additional services. Many of the errors will continue to depend upon the relative dynamics of practice populations, name changes, addresses, and civil states on the one hand, and of the updating system on the other. A really effective general purpose health care register would require the integral design of a master-file/sub-file transfer system so that all sub-systems (general practice, cervical cytology, immunization, etc.) could be kept in step with each other and so that changes (e.g., of address) reported to any sub-system were transferred to the master-file and to all relevant sub-files.

The updating system would need to be formalized and automated and separate enquiry/correction 
procedures would need to be designed for mutable and immutable information fields. Some items of data might well be abandoned, for example civil state, and others might eventually need to be redesigned (e.g., NHS number). In effect, the necessary development would need to depart from the concept of a remuneration file with possible additional uses, and move towards the concept of a file for health care purposes, of which the general practitioner contract function was a subset. Primary registration would therefore be with the National Health Service; registration with a general practitioner would be a secondary-file function.

We are aware that although this approach corresponds logically with the concept of the total health care responsibilities of area, region, and district administrations within the new health service structure, it conflicts with some views on the relationship between general practitioners and other doctors, and it raises questions of relationships between doctors and nurses and other professional health care workers. It also requires explicit decisions on the nature of modern medical care and (technical questions aside) does not permit continued ambivalence regarding responsibilities to maintain health in those without complaint. We do not wish to develop these issues here, only to make the point that if it is accepted that the responsibility of the NHS includes contributions to the maintenance of health, then registers are necessary and must be purpose-designed. A master register could be developed from existing general practitioner and Executive Council lists and probably should be, but the present system will not itself meet the need. In lieu of such a system, and until it is developed, we shall be forced to continue the expensive multiplication of less than satisfactory independent subsystems.

\section{REFERENCES}

Farmer, R. D. T. and Cross, K. W. (1972). An automated records system for general practice. Brit. J. prev. soc. Med., 26, 148.

and - (1973). The National Health Service number. Brit. J. prev. soc. Med., 27, 53. 